\title{
Performance of Passive Boost Switched Reluctance Converter for Single-phase Switched Reluctance Motor
}

\author{
Jin-Woo Ahn* and Dong-Hee Lee ${ }^{\dagger}$
}

\begin{abstract}
A novel passive boost power converter forsingle-phaseswitched reluctance motor is presented. A simple passive circuit is proposed comprisingthree diodes and one capacitor. The passive circuitis added in the front-end of a conventional asymmetric converter to obtain high negative bias. Based on this passive network, the terminal voltage of the converter side is a general DC-link voltage level in parallel mode up to a double DC-link voltage level in series mode. Thus,it can suppress the negative torque generation from the tail current and improve the output power. The results of the comparative simulation and experiments forthe conventional and proposed converter verify the performance of the proposed converter.
\end{abstract}

Keywords: Switched reluctance motor, Passive boost power converter, High demagnetization voltage

\section{Introduction}

Switched Reluctance Motor (SRM) is a popular research topic because its mechanical strength and cost advantages can lead towide industrial applications[1-2]. Converter technology is one of the most populartopics in SR drive as proven by the numerous studies being conducted. The buck-boost converter is used in Switched Reluctance(SR) converter to boost the demagnetization voltage[3-9]. However, the converter's high cost and complicated boost voltage control method limitits applications.

As part of a converter, the front-end determines the voltage level and performance of an SR converter. The passive boost converter is simple and requiresonly minimalextra cost, yetits performance is better than the conventional asymmetric converter.

The use of series-parallel front-end to construct a novel passive converter is proposed. The proposed passive converter is introducedbecausedifferent operation modes occur during single-phase excitation and phase commutation. For a single-phase SR drive, the operational modes for the proposed converter are presented in detail. Due to the high demagnetization voltage of the proposed converter, both the long tail current and the negative torque arereduced in high-speed applications.

\section{Single-phase SRMdrive}

\subsection{Conventional Asymmetric Converter}

The conventional SR drive uses a diode bridge rectifier

$\dagger$ Corresponding Author: Departmentof Mechatronics Engineering, Kyungsung University, Korea. (leedh@ks.ac.kr)

* Department of Mechatronics Engineering, Kyungsung University, Korea. (jwahn@ks.ac.kr)

Received: August 21, 2010; Accepted: March 8, 2011 and a large capacitor in the front-end. Thecapacitor maintainsa steady DC-link voltage, acting as a lowpass filter. Another function of the DC-link capacitor is as storage of the magnetic field energy when the SRM is demagnetized.

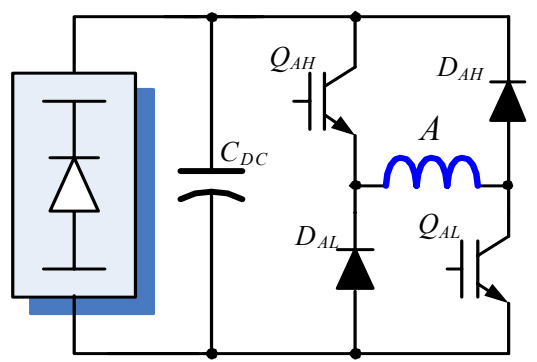

Fig. 1. Conventional single-phase SR drive

The asymmetric bridge converter,which is very popular for SR drives, consists of two power switches and two diodes per phase. This type of SR drive can support the independent control of each phase and handle phase overlap. The asymmetric converter has three modes, namely, magnetization mode, freewheeling mode, and demagnetization mode. These are shown in Fig. 2.

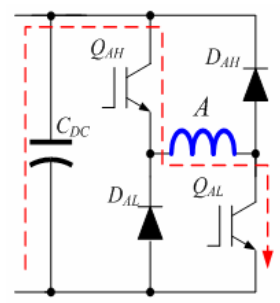

(a)

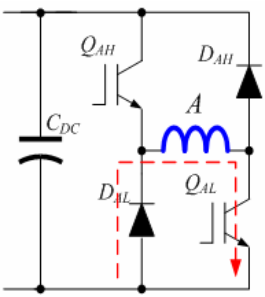

(b)

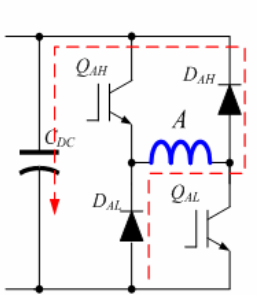

(c)
Fig. 2. Operation modes of asymmetric converter: (a) Magnetization, (b) Freewheeling, and (c) Demagnetization 
In Figs. 2(a) and 2(c), the amplitudes of the excitation and demagnetization voltage are close to the terminal voltage of the filter capacitor. The fixed DC-link voltage limits the performance of the SR drive in high-speed applications.

A high demagnetization voltage can improve the output torque and high-speed performance of the SR drive[2]. In Fig. 3, twoadvantages of high demagnetization areshown. One, it has the abilityto reduce the negative torque. Two, the dwell angle can be extended. Thus, average torque and efficiency canbe increased.

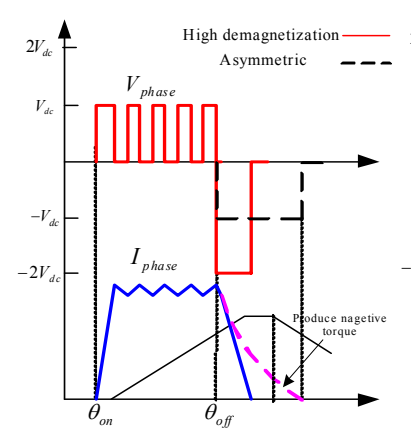

(a)

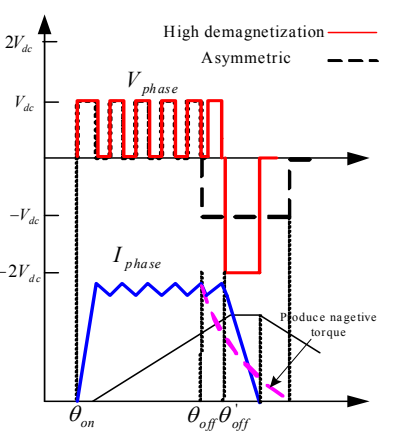

(b)
Fig. 3. Advantages of high demagnetization voltage: (a) Negative torque reduction, and (b) Extended dwell angle

\subsection{Proposed Passive Boost Converter}

A novel passive boost power converter for the singlephase SR drive is shown in Fig. 4. Compared with the conventional converter, the proposed converter adds three diodes and one capacitor. The passive boost converter is formed by the additional components and the DC-link capacitor. It is a four-terminal network as shown in Fig. 5(a). This circuit has three modes, input mode 1, output mode, and input mode 2 (Fig. 5).

In input mode 1 , the DC source charges the DC-link capacitor $C_{l}$ from the $a b$ terminal. In this setup, the voltage of $C_{l}$ keeps the voltage balance with the DC source, which cannot charge the boost capacitor $C_{2}$ because of the reverse diode $D_{3}$.

In output mode, the two capacitors and diodes from the

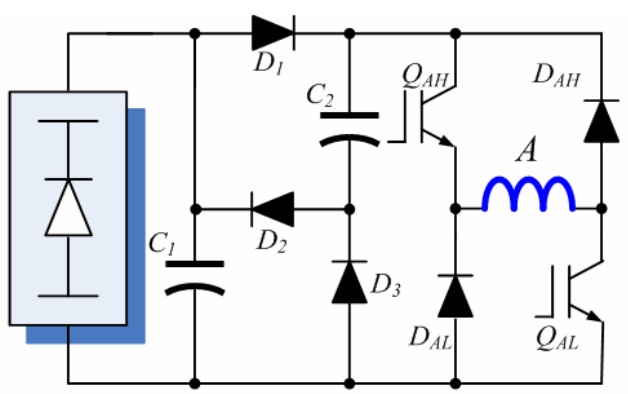

Fig. 4. Proposed passive boost single-phase converter two independent voltage sources are in parallel as shown in Fig. 5(c). Thus, the output voltage of the $c d$ terminal is equal to the maximum voltage of each capacitor. Moreover,the energy is supplied by one or both capacitors as determined by the voltage of the two capacitors.

In input mode 2, the energy is input from the $c d$ terminal. When the diode $D_{2}$ conducts, $\operatorname{diodes} D_{1}$ and $D_{3}$ stopconducting. The input current charges the two capacitors using diode $D_{2}$. The two capacitors are connected in series and the voltage of the $c d$ terminal is the superposition voltage of both. This is shown in Fig. 5(d).

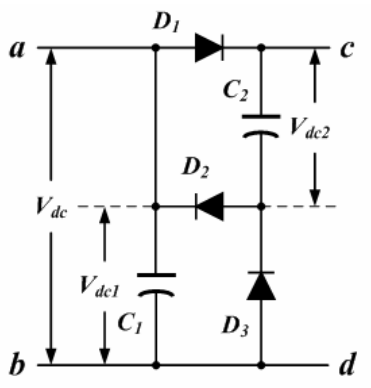

(a)

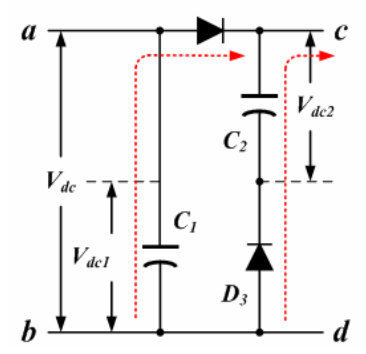

(c)

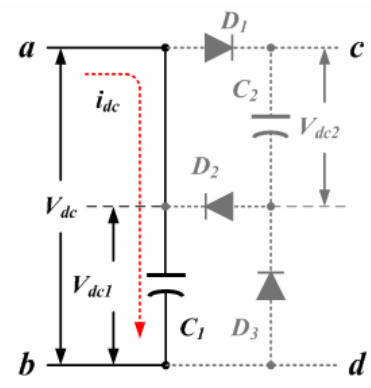

(b)

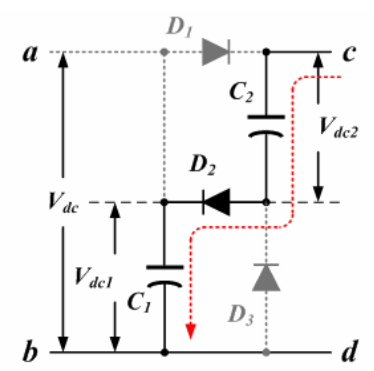

(d)
Fig. 5. Passive capacitor circuit and operation modes: (a) Passive capacitor circuit, (b) Input mode 1, (c) Output mode, and (d) Input mode 2

When the asymmetric converter works in the excitation mode, the passive boost circuit and the asymmetric converter are combined and producea maximum excitation voltage by connecting the two capacitors in parallel. In the demagnetization mode, the two capacitors are connected in series. Consequently, the phase winding of the motor obtains the general DC-link voltage in the excitation mode and the double DC-link voltage in the demagnetization mode.

To evaluate all combinations of the passive boost circuit and the asymmetric converter, the modes of the proposed converter are divided into five modes based on thedifferent states of switches: boost capacitor excitation mode, DClink capacitor excitation mode, two-capacitor excitation mode, freewheeling mode, and fast demagnetization mode. These are shown in Fig. 6.

Compared with the asymmetric converter, the excitation mode is divided into three states from different boost 
capacitor voltages. These are thevoltage state, switch state, and the phase voltage state as shown in Table 1.

The size of the boost capacitor should be sufficient to store the recovered energy from the demagnetization. To select a boost capacitor in the proposed converter, the initial boost voltage and an acceptable voltage ripple are considered. Using the characteristic of the proposed converterand assuming thatthe voltage of the boost capacitor $C_{2}$ is charged up to $V_{C 2}=V_{C 1}$, the maximum voltage ripple of the boost capacitor is considered in single pulse control without current overlap.

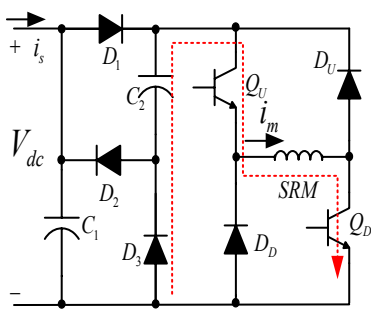

(a)

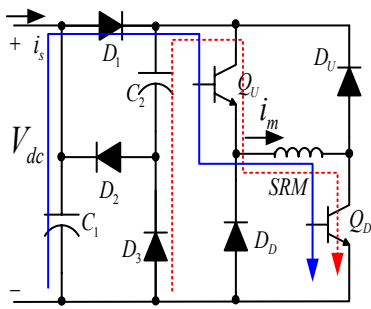

(c)

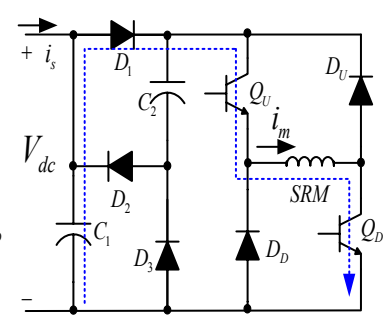

(b)

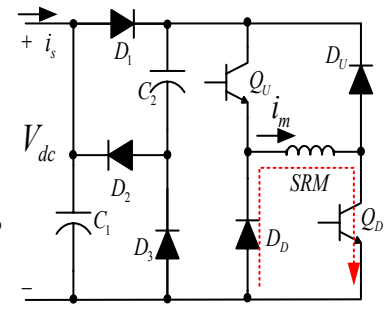

(d)

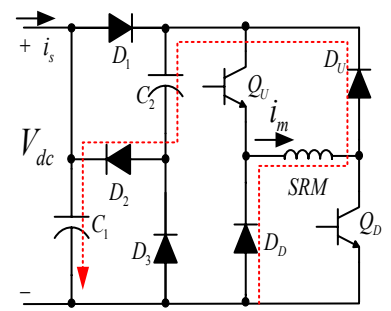

(e)

Fig. 6. Operation modes of the proposed converter: (a) Boost capacitor excitation, (b) DC-link capacitor, Excitation, (c) Two capacitors excitation, (d) Freewheeling, and (e) Fast demagnetization

Table 1. Operation modes of proposed converter

\begin{tabular}{c|c|l|l}
\hline Mode & Voltage state & \multicolumn{1}{c}{ Switch State } & \multicolumn{1}{c}{ Phase Voltage } \\
\hline Excitation-1 & $V_{C_{1}}<V_{C_{2}}$ & $\begin{array}{l}\left(Q_{u}, Q_{d}, D_{3}\right) \text { on } \\
\left(D_{1}, D_{2}, D_{U}, D_{D}\right) \text { off }\end{array}$ & $V_{C 2}-V_{D}-2 V_{Q}$ \\
\hline Excitation-2 & $V_{C_{1}}>V_{C_{2}}$ & $\begin{array}{l}\left(Q_{u}, Q_{d}, D_{1}\right) \text { on } \\
\left(D_{2}, D_{3}, D_{U}, D_{D}\right) \text { off }\end{array}$ & $V_{C 1}-V_{D}-2 V_{Q}$ \\
\hline Excitation-3 & $V_{C_{1}}=V_{C_{2}}$ & $\begin{array}{l}\left(Q_{u}, Q_{d}, D_{1}, D_{3}\right) \text { on } \\
\left(D_{2}, D_{U}, D_{D}\right) \text { off }\end{array}$ & $V_{C 2}-V_{D}-2 V_{Q}$ \\
\hline Freewheeling & & $\begin{array}{l}\left(Q_{d}, D_{D}\right) \text { on } \\
\left(Q_{u}, D_{l}, D_{2}, D_{3}, D_{U}\right) \text { off }\end{array}$ & $-\left(V_{D}+V_{Q}\right)$ \\
\hline Demag. & & $\begin{array}{l}\left(D_{U}, D_{D}, D_{2}\right) \text { on } \\
\left(Q_{u}, Q_{d}, D_{2}, D_{3}\right) \text { off }\end{array}$ & $-\left(V_{C_{1}}+V_{C_{2}}+3 V_{D}\right)$ \\
\hline
\end{tabular}

Fig. 7 shows the charge-discharge cycle of the boost capacitor in single pulse operation. The energy of the boost capacitor is discharged to build up the phase current during the excitation stage. Based on the discharge of the boost capacitor, the voltage of the boost capacitor is decreased to the DC-link voltage $V_{D C}$. After the turn off angle, the recovered energy charges the two capacitors in series. The charged voltage from the recovered energy in demagnetization mode is given by:

$$
\Delta V=\frac{1}{C_{2}} \int_{0}^{t_{f}} i_{p h} d t
$$

Where $t_{f}$ is the demagnetization time and $i_{p h}$ is the phase current of the motor in demagnetization mode.

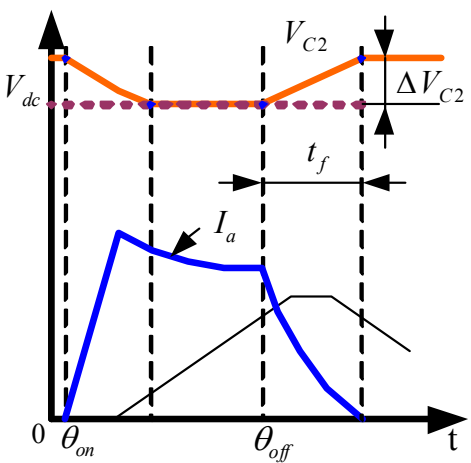

Fig. 7. Charge-discharge cycle of the boost capacitor

\section{Simulations and experiments}

\subsection{Simulation Results}

In order to verify the performance, the proposed converter was simulated using Matlab/Simulink. A 3D drawing of prototype 6/6 SRM is shown in Fig. 8(a). Based on the dimensions of the prototype motor, the $2 \mathrm{D}$ finite element analysis was conducted. The inductance characteristic of the prototype SRM is shown in Fig. 8(b).

A control block diagram for the proposed single-phase SR drive is shown in Fig. 9. The single-phase SR drive system contains a speed controller, a current controller, a switching pattern state machine, an angle controller, a speed estimator, a position detector, and an encoder.

The simulation results comparing the conventional and proposed converter are shown in Fig. 10 and Fig. 11, respectively. The simulation used MatlabSimulink and SimPowerSystemstoolbox. In Fig. 11, soft-chopping is applied between the turn on and the turn off angle. The excitation voltage is the same as the DC-link voltage. The double DC-link demagnetization voltage is clearly seen in the simulation results. The high demagnetization voltage of the proposed converter obtains a short tail current and reduces the negative torque after the aligned position. The 


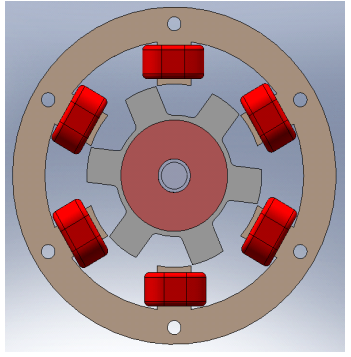

(a)

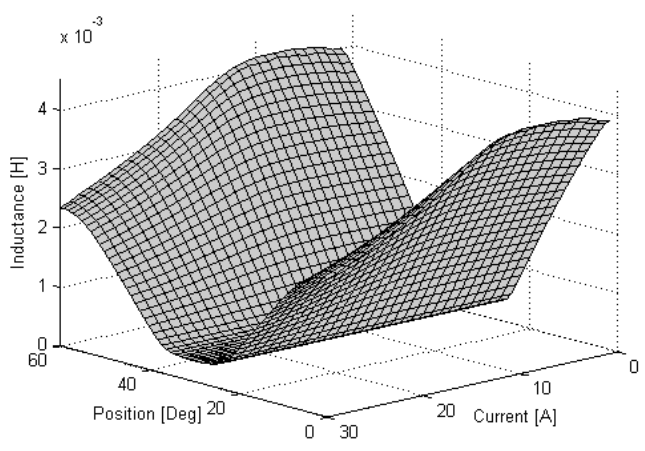

(b)

Fig. 8. Prototype of 6/6 SRMandinductance characteristics: (a) Prototype motor, and (b) Inductance profile

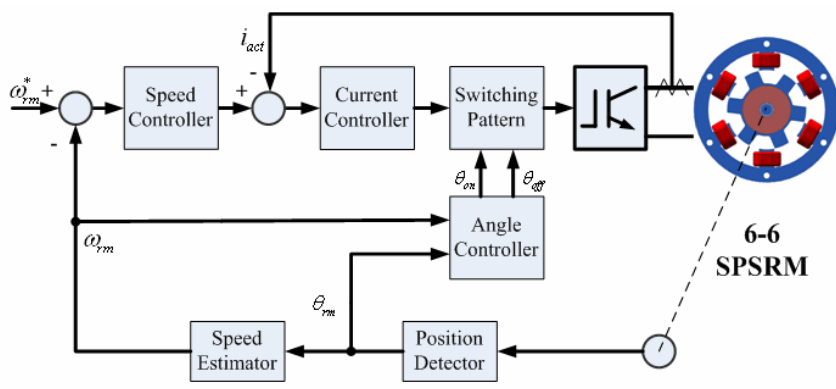

Fig. 9. Control block diagram of proposed drive

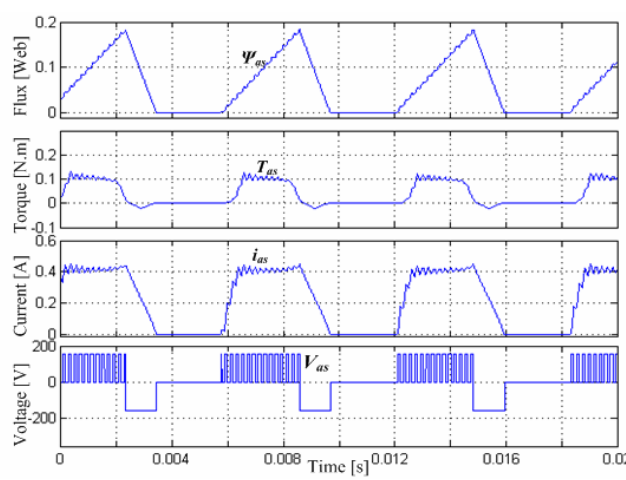

(a)
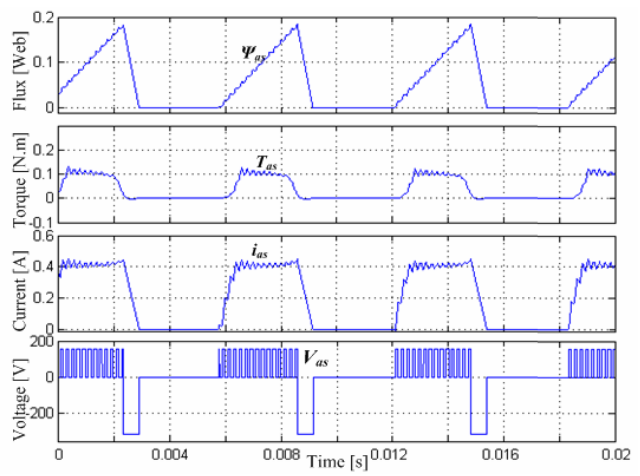

(b)

Fig. 10. Comparison of two converters in PWM control: (a) Conventional, and (b) Proposed

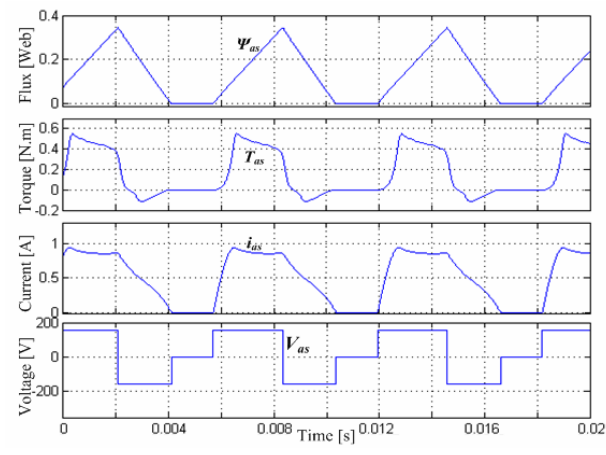

(a)

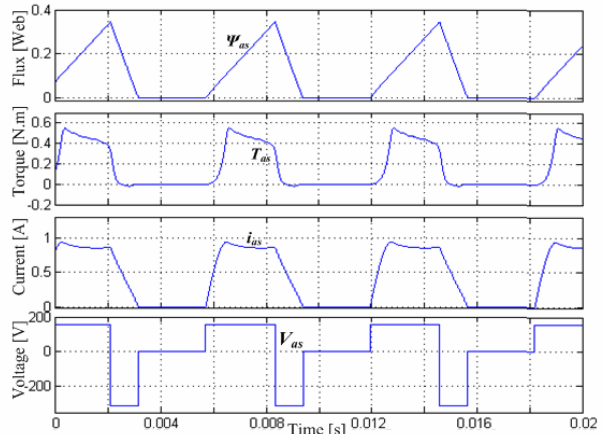

(b)

Fig. 11. Comparison of two converters in single pulse control: (a) Conventional, and (b) Proposed 
two converters operatingwith the single pulse control is shown in Fig. 11. The excitation and demagnetization voltage are the same as those for PWM control.

The increased output power can be seen from the increased area enclosed by the flux verse current trajectory in Fig. 12. The increase of output power, which is proportional to the closed locus of flux and current,is shown clearly.

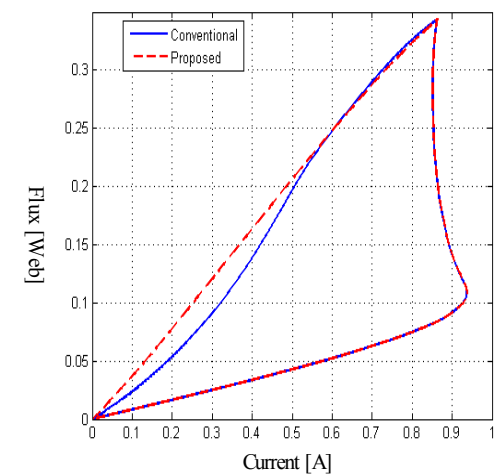

Fig. 12. Flux verse current trajectory in single pulse control

\subsection{Experimental Results}

To test the performance of the proposed converter, a main controller board using DSP TMS320F2812 and the converter hardware wasconstructed.

TI DSP TMS320F2812 is a high-performance processor used for this control board. The clock frequency of TMS320F2812, which is up to 150MIPS performance, integrates a complete set of control system capabilities: PWM generation, time stamping, sensor capture, A/D converter, communication interfaces, program, and data storage. Theseallow highly accurate and complicated control algorithms.

The block diagram of the control board is shown in Fig. 13. The encoder signal is received by QEP and capture interface. Rotor position estimation and speed calculation can be obtained from these modules. The current signals and voltage signals are inputted to a signal conditioning circuit. They are then detected by the A/D converter interface of DSP. Consequently, the turnon, turnoff, and speed reference signals are generated by variable resistors and received by the A/D converter interface. The control algorithm of the presentexperiment uses PI controller for speed control and hysteresis controller for current control. All of the calculationsareoperated in the DSPcore. Softchopping is used to reduce switching loss. The upper side of the power switches applies the PWM switching, and the lower side usesthe I/O output. Important information such as speed, turnon angle, and turnoff angle can also be sent to an LCD display, and some instantaneous data can be shown from the D/A converter which uses the SPI port on the DSP.

The experimental converter is an asymmetric converter

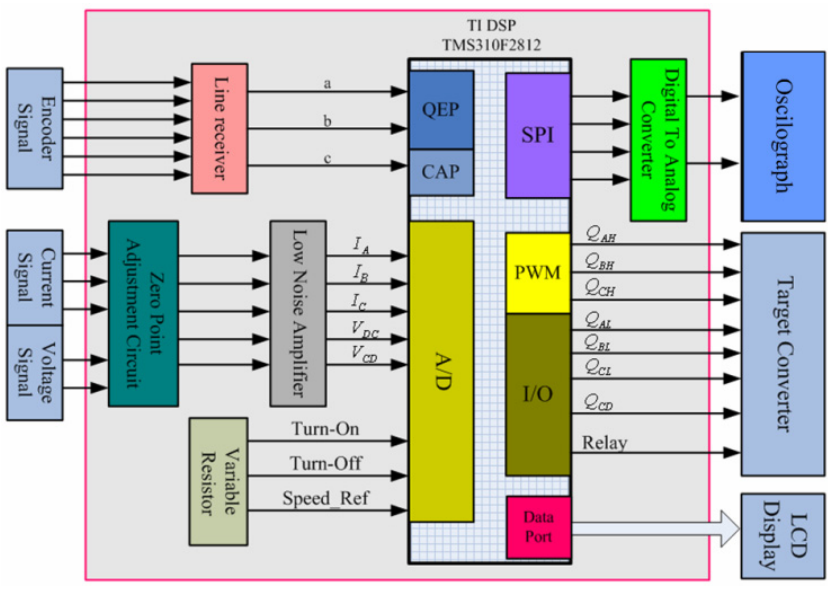

Fig. 13. Block diagram of the control board

with two capacitors connected in series and one additional power switch. When the boost capacitor is shorted, theconverter is operated as a conventional asymmetric converter. When the two proposed front-end circuits are connected to the converter, two additional proposed converters are constructed. In theconverter connected with front-end circuits, four isolation DC-DC converters are used for 4 floating IGBTs, and one is used to the common groundingof the three low sides of IGBT. HCPL-3120 is used to isolate the IGBT gate drive. Lastly, four current sensors and two voltage sensors are used to detect the current and voltage signals, respectively.

The input voltage of the converter is $78[\mathrm{~V}] \mathrm{AC}$. Thus, the DC-link voltage of the converter is approximately 100[V]. In Fig. 14(a), excitation and demagnetization voltage of the conventional converter is $100[\mathrm{~V}]$ in the current control and the angle position control. Therefore, both excitation and demagnetization voltages are fixed for the asymmetric converter.

To improve the performance of the SR converter, the proposed passive converter is used. In Figs. 14 and 15, the excitation voltage of the proposed converter is $100[\mathrm{~V}]$, but the demagnetization voltage of the proposed converter is up to $200[\mathrm{~V}]$. As a result, the excitation voltage is the same as the DC-link voltage and the demagnetization voltage is twice that of the DC-link voltage.

Therefore, fast demagnetization voltage reduces the tail current, which improves drive performance by reducing negative torque. In Fig. 15, the voltage ripple appears in the boost capacitor when a small capacitor is used. The magnitude of voltage ripple varies with different load conditions. When a big capacitor is used, the voltage ripple of the boost capacitor can be ignored.In the experimental results for the proposed converter, the voltage of the boost capacitor is shown as a straight line in Fig. 16. The voltage of the boost capacitor is about 100[V]. Thus, the boost voltage is the same as the DC-link voltage. The turn-on and turn-off angles are easy to predict and design because of the stable boost voltage. 


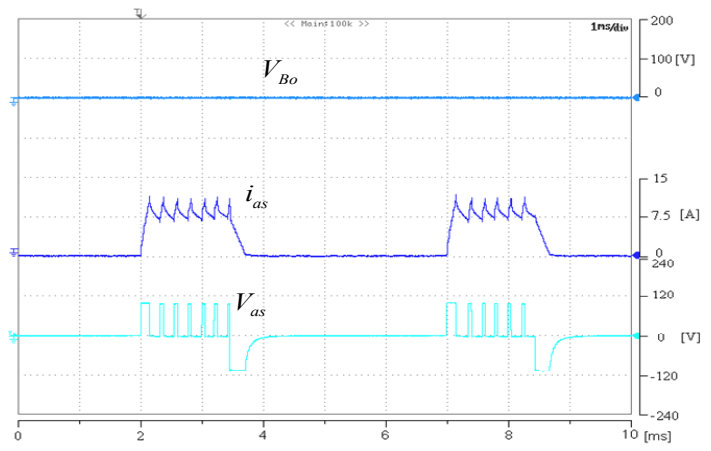

(a)

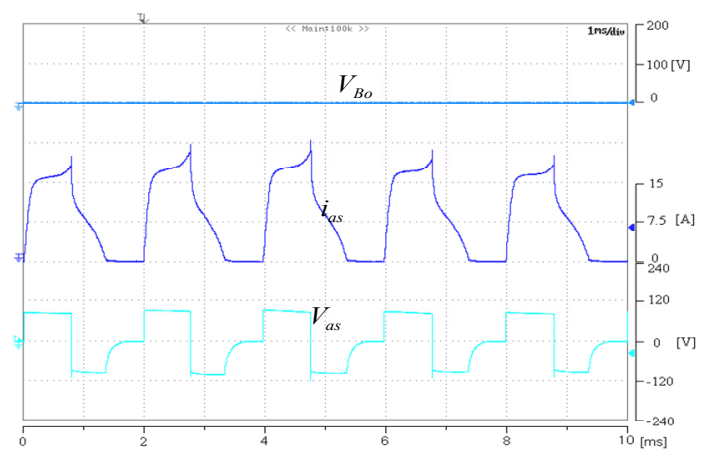

(b)

Fig. 14. Experimental results of the asymmetric converter: (a) Current control (2000[rpm]), and (b) Angle position control $(5000[\mathrm{rpm}])$

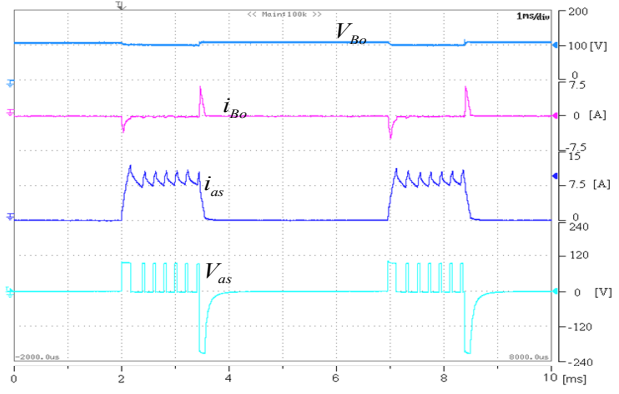

(a)

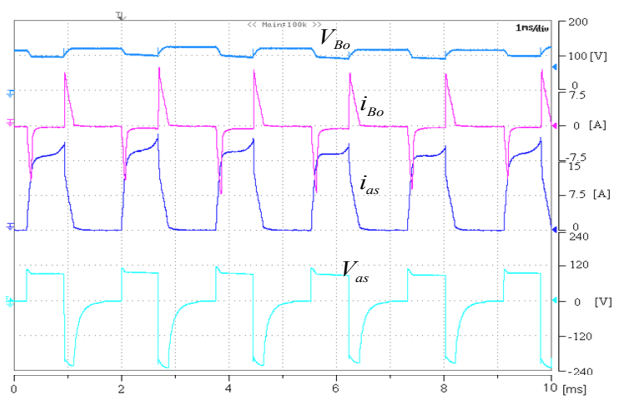

(b)

Fig. 15. Experimental results of the proposed passive converter (47[uF]): (a) Current control $(2000[\mathrm{rpm}])$, and (b) Angle position control (5000[rpm])

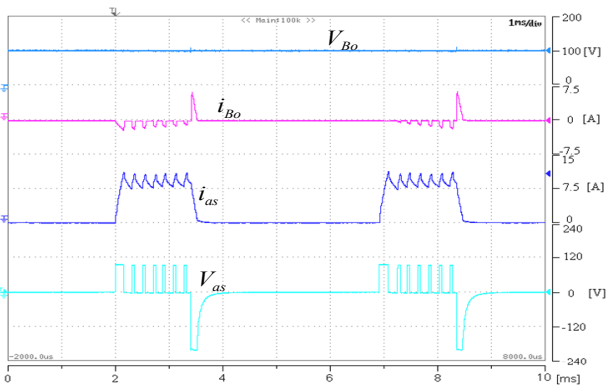

(a)

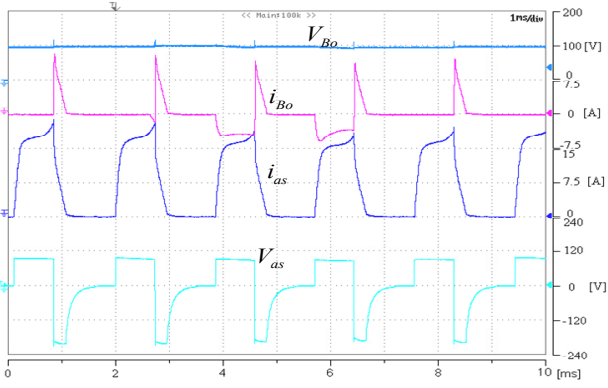

(b)

Fig. 16. Experimental results of proposed passiveconverter (680[uF]): (a) Current control (2000[rpm]), and (b) Angle position control (5000[rpm])

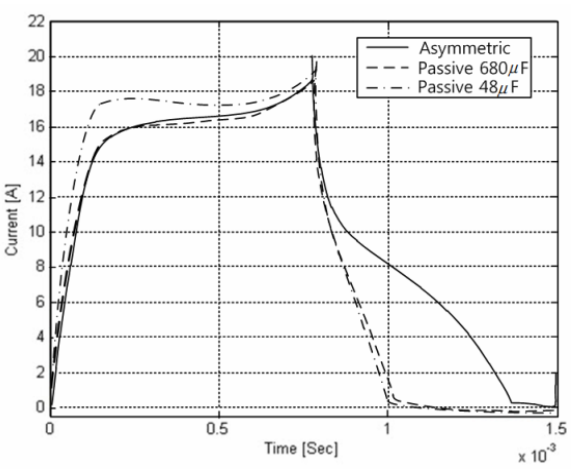

(a)

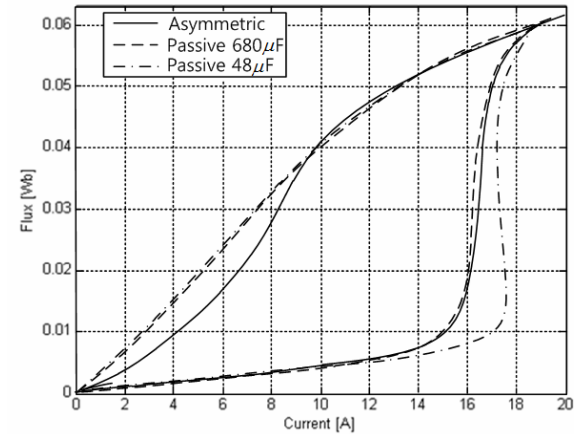

(b)

Fig. 17. Comparison results of three converters underthe same conditions: (a) Phase current, and (b) Flux versus current trajectory 
A comparison of the three converters is shown in Fig. 17. The motor worked on the same turnon angle, turnoff angle, and speed. The tail current of the asymmetric converter is longer than the others becausethe demagnetization voltage is equal to the DC-link voltage. When a $47 \mathrm{uF}$ boost capacitor is used, only a small boost voltage affects the phase winding and slightly increases the phase current. The flux linkage versus current trajectory of the three converters is shown in Fig. 17. When the trajectory area is increased, the output power should be increased.

\section{Conclusion}

In this paper, a novel power converter for single-phase SRM with high demagnetization voltage is proposed. A passive capacitor circuit is added to the converter front-end. Severalextra passive components are required and voltage rating of the power switch should be increased, which may increase the cost ofthe proposed converter. However, based on this passive network, the two capacitors can be connected in series and in parallel, obtaining twice the DClink voltage during demagnetization. Due to the high demagnetization voltage, the efficiency and output power could be improved. Computer simulations and experimental results have verified the performance of the proposed converter.

\section{Acknowledgement}

This work was supported by a grant from the National Research Foundation of Korea(NRF) funded by the KoreanGovernment (Grant No. 2010-0014172).

\section{References}

[1] R. Krishnan, "Switched Reluctance Motor Drives: Modeling, Simulation, Analysis, Design, and Applications", CRC Press, 2001.

[2] Jin-Woo Ahn, "Torque Control-Chap.8 Switched Reluctance

Motor",http://www.intechopen.com/articles/show/titl e/switched-reluctance-motor,Intech Publisher. Feb, 2011.

[3] A. Dahmane, F. Meebody, F.-M.Sargos, "A novel boost capacitor circuit to enhance the performance of the switched reluctance motor", Power Electronics Specialists Conference, 2001. 17-21 June 2001 pp:844 - 849.

[4] S. Chan, H. R. Bolton, "Performance enhancement of single-phase switched-reluctance motor by DC link voltage boosting", Electric Power Applications, IEE Proceedings B Vol 140,Issue 5, vol.2, Sept. 1993 pp:316-322.
[5] K. I. Hwu, C. M. Liaw, "DC-link voltage boosting and switching control for switched reluctance motor drives" Electric Power Applications, Vol 147, Issue 5, Sept. 2000 pp:337 - 344 .

[6] J. D. Lewis, H. R. Bolton, and N. W. Phillips, "Performance enhancement of single and two phase SR drives using a capacitor boost circuit," in European Power Electronics and Applications Conf. Rec., vol. 3, 1995, pp: 229-232.

[7] G. Dessouky, B. W. Williams, and J. E. Fletcher, “A novel power converter with voltage boosting capacitors for a four-phase SRM drive," IEEE Trans. Ind. Electron., vol. 45, no. 5, pp: 815-823, Oct. 1998.

[8] J. Liang, D.-H. Lee, J.-W. Ahn, "Direct instantaneous torque control of switched reluctance machines using 4-level converters", Electric Power Applications, IET Transactions on, Vol. 3, Issue: 4 July 2009, pp: 313323.

[9] J. Liang, D.-H. Lee,J.-W. Ahn, “Analysis of Passive Boost Converter for Three-Phase SR Drive,'IEEE Trans. Ind. Electron., vol. 57, no.9, pp:2961-2971, Sep. 2010.

[10] D.-H. Lee, J. Liang, J.-W.Ahn, "Series-Parallel connected capacitor type boost conveter for a singlephase SRM," Journal of Power Electronics, Vol.10, No.4, pp388 395,July 2010

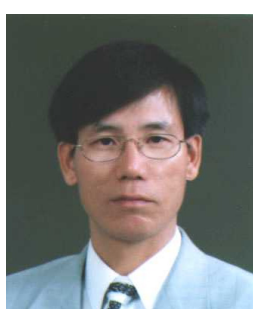

Jin-Woo Ahn was born in Busan, Korea, in 1958. He received his B.S., M.S., and Ph.D. in Electrical Engineering degrees from Pusan National University, Busan, Korea in 1984, 1986, and 1992, respectively.He has been with Kyungsung University, Busan, Korea, since 1992 as aprofessor in the Department of Mechatronics Engineering. He was a visiting researcher in the Speed Lab at Glasgow University, U.K., a visiting professor in the departments of ECE and WEMPECat the University of Wisconsin-Madison, USA, and a visiting professor in the Department of ECE at Virginia Tech. from 2006 to 2007. He was the director of the Advance Electric Machinery and Power Electronics Center(2004-2008). He has been the director of the Smart Mechatronics Advanced Research and Training Center since August 2008 and the Senior Easy Life Regional Innovation System since July 2008. These two research centers are authorized by the Ministry of Knowledge Economy, Korea. He is the author of five books including SRM as well as the author of more than 120 papers. He holdsmore than 10 patents including 3 U.S. patents. His current research interests includeadvanced motor drive systems and electric vehicle drives.

Dr. Ahn has received several awards including Best Paper Award(2002), Academic Achievement Award(2003), Park Min-Ho Academic Award(2009) from the Korean Institute 
of Electrical Engineers, Best Paper Award(2003) from the Korean Federation of Science and Technology,Academic Achievement Award(2003), Technology Achievement Award(2004), Best Paper Award(2007)from Korean Institute of Power Electronics.Similarly, he was bestowed with the following honors: Best Research Professor(2008), Best Industrial Cooperation Award(2009), and Merit Award(2009, 2010) from Kyungsung University.He is a Fellowof the Korean Institute of Electrical Engineers, a member of the Korean Institute of Power Electronics, and a senior member of the Institute of Electrical and Electronics Engineers. He is theChairman of the Academic Committee ofKIEE and the vice president of Korea Regional Innovation System Association.

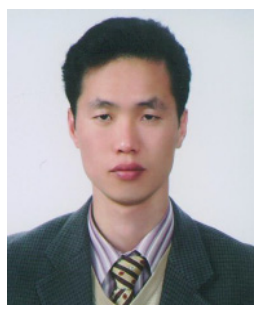

Dong-Hee Lee was born on November 11, 1970. He received his B.S, M.S., and $\mathrm{Ph}$. D. in Electrical Engineering degrees from Pusan National University, Busan, Korea in 1996, 1998, and 2001, respectively. $\mathrm{He}$ worked as a Senior Researcher for the Servo R\&D Team at OTIS-LG from 2002 to 2005. Since 2005, he has been with Kyungsung University, Busan, Korea as an assistant professor in the Department of Electrical and Mechatronics Engineering. He serves asdirector of the Advance Electric Machinery and Power Electronics Center since 2009. His current research interests are servo systems and electrical motor drives with power electronics. 